\title{
长叶车前花叶病毒蛋白亚基不同聚集形态 对抗原专化性的作用
}

朱培坤 陆妙康王鸣歧

（复旦大学生物系,上海）

植物病毒外壳蛋白, 具有向病毒粒体或向相同蛋白形态部分聚合的性质. 为研究烟草花 叶病毒(Tobacco Mosaic Virus, TMV) 蛋白亚基不同聚集形态的抗原专化性, Van Regenmortel 用琥珀酰䣶 (Succinylation) 处理病毒外壳蛋白从而使蛋白亚基保持单体状态的 ${ }^{[1]}$. 后来,他又 指出琥珀酰䣲的处理, 虽使蛋白亚基保持单体状态, 但却改变蛋白质的抗原专化性, 因而使实 验结果难以解释 ${ }^{[2]}$. 不少学者的工作证明, 用一定浓度的甲醛处理病毒蛋白, 可使衣壳蛋白 保持稳定状态, 而抗原专化性不发生任何变化 ${ }^{[3,4]}$. 本工作所用长叶车前花叶病 毒 (Ribgrass Mosaic Virus, RMV) 粒体制备液,经电镜观察认为是病毒粒体、破碎的粒体以及因病毒破碎而 产生的各种外壳蛋白盘状体和聚集体(包括游离的亚基单体)的混合物, 但这种混合物以病毒 粒体为主. 所用病毒外壳蛋白制备液, 是外壳蛋白各种盘状体和聚集体（包括游离的亚基单 体)的混合物. 所用由甲醛处理的病毒蛋白制备液, 是相对稳定的亚基单体(包括可能存在微 少的尚未完全解离的蛋白亚基聚集体和甲醛停止处理后亚基单体重新组合的聚集体).

\section{材 料 和 方 法}

\section{RMV 及其抗血清的制备 见文献 [5] 和 [6].}

2. RMV 外恋蛋白及其抗血清的制备 用两倍体积的冰乙酸, 在冰浴搅拌下处理病毒 溶液, 20 分钟后将上述溶液移入冰箱静置 3 小时,离心 $(3,500$ 转/分, 30 分钟)去核酸沉淀,将 上清液用等量冷水稀释,对水透析 $2-3$ 天 $\left(3^{\circ} \mathrm{C}\right)$, 加几滴 $3 M \mathrm{pH} 4.7$ 醋酸钠缓冲液,使蛋白凝 集, 高速离心 $(10,000$ 转/分, 1 小时) 得沉降物, 加人适量冷水使沉降物再溶, 然后滴加稀氢氧 化钠调节 $\mathrm{pH}$ 为 7.5 左右, 再经超离心 (35,000 转/分, 1.5 小时)去除末降解的病毒, 上清液即为 RMV 外壳蛋白溶液 ${ }^{[7]}$. 用外壳蛋白溶液接种指示植物心叶烟无枯斑发生, SDS 降解后聚丙 烯酰胺凝胶电泳为单一条带; 测紫外分光光度值, $280 \mathrm{~nm}$ 处有最高吸收峰. 免疫时, 每只家兔 共注射外壳蛋白 $13 \mathrm{mg}$ 左右, 分 5 次福氏非完全佐剂法进行皮下、肌肉多点注射,休息一周后采 抗血清, 免疫双扩散测效价, 当外莣蛋白为 $0.1 \mathrm{mg} / \mathrm{ml}$ 的浓度时仍产生沉淀线.

3. RMV 外壳蛋白亚基单体及其抗血清的制备按文献所给的方法, 首先 配制 $0.7 \mu$ $\mathrm{pH} 7.25$ 焦磷酸盐缓冲液, 在酸度计上用 $5 \mathrm{NHCl}(\mathrm{AR})$ 调 $\mathrm{pH}$ 为 7.25 , 然后加入浓度为 $36-$ $38 \%$ 的甲醛,使其终浓度为 $0.35 \%$. 将外壳蛋白溶液装人透析袋, 放人上述含甲醛的缓冲液中 透析一周, 得 RMV 外壳蛋白亚基单体制备液, 此液免疫家兔, 每只家兔 $9 \mathrm{mg}$ 左右, 分 5 次福氏

本文 1982 年 4 月 19 日收到. 
非完全佐剂法进行皮下、肌肉多点注射,休息一周后采抗血清,免疫双扩散测效价, 当 RMV外 壳蛋白亚基单体为 $0.08 \mathrm{mg} / \mathrm{ml}$ 浓度时仍产生沉腚线.

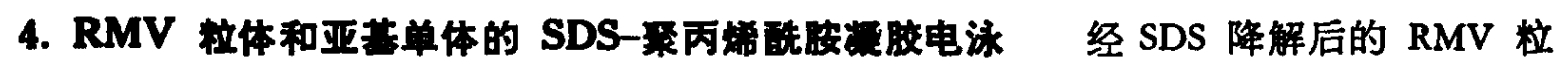
体和亚基单体分别装管同时进行 SDS-聚丙烯酰胺镜电泳，在电泳条件相同的情况下，得到 移动距离相等的染色带 (图 1). 由于经 SDS 降解后的 RMV 粒体在 SDS一聚丙烯酰胺凝胶电泳时所得的染色带 是亚基单体的移动所造成的,因此,所得移动距离相等的 染色带,显示经甲醴处理的外壳蛋白已解离成亚基单体.

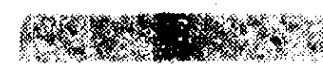

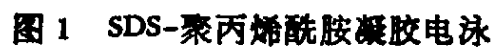
上为 SDS 降解的病毒祊体; 下为甲監处理的亚基单体
5. 对流免疾电泳电泳缓冲液、配胶缓冲液均为

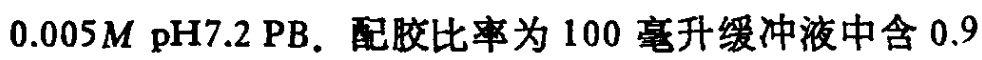
克琼脂糖 (上海东海制药厂) 和 0.1 克 $\mathrm{NaN}_{3}$. 每块载玻 片 $(76 \times 26 \mathrm{~mm})$ 铺 $3 \mathrm{ml}$ 琼脂糖液, 固后打孔, 孔径 $3 \mathrm{~mm}$, 孔对距 $4 \mathrm{~mm}$, 孔距 $1.5 \mathrm{~mm}$. 电压 $150 \mathrm{~V}$, 电泳 2 小 时,抗原和抗血清量均为 $10 \mu \mathrm{l}$ ，抗血清孔端接正极. 电泳后 $37^{\circ} \mathrm{C}$ 保湿过夜. 次日，用生理盐 水浸洗 2-3 天 (经常换水)，然后在琼脂榶表面数贴洁纸，放烘箱 $60^{\circ} \mathrm{C}$ 烘干，考马斯亮蓝染 色.

6.免宾电泳上述琼脂糖板, 中间挖一长约 $45 \mathrm{~mm}$, 宽约 $2 \mathrm{~mm}$ 的抗血清穴棤, 电压 $100 \mathrm{~V}$, 电泳 2 小时. 抗原孔穴加人抗原 $10 \mu \mathrm{l}$, 抗血清穴槽加抗血清 $0.3 \mathrm{ml}$ (电泳毕加抗血清), $370 \mathrm{C}$ 温箱扩散过夜, 然后浸洗, 栱干,染色与脱色.

7. 双向免菠扩调述琼脂糖板,按适当格式打孔，孔径 $5 \mathrm{~mm}$, 孔距 $2 \mathrm{~mm}$, 每孔六分别 加满抗原或抗血清, 379 C 温箱扩散过夜, 依上法漫洗, 烘干、染色与脱色:

\section{结果与讨论}

本实验,当 RMV 抗血清和 RMV、RMV 外壳蛋白, RMV 亚基单体进行双向免废扩散, 观察到亚基单体孔穴与 RMV 抗血清孔穴之间生成一条免度沉淀线, 外壳蛋白孔穴与 RMV 抗血清孔穴之间生成两条免疫沉定线, 其中近抗血清孔穴的沉淀线与亚基单体孔穴处的沉腚 线相吻合，而另一条则不相交; RMV 孔穴与 RMV 抗血清孔穴之间生成两条颜色甚深的免庭 沉淀线,一条近抗原孔穴, 另一条近抗血清孔穴并且其一端逐渐与外壳蛋白孔穴处的一条沉淀 线相交联（图 2)，说明 RMV、RMV 外壳蛋白，RMV 亚基单体制备液与 RMV 抗血清发生 既不同又有某些相同的免疫反应, 进而表明它们的抗原专化性既有不同性又有相似性. 当 RMV 抗血清和 RMV、RMV 外壳蛋白、RMV 亚基单体进行对流免废电泳时,观察到在抗原 与抗血清孔穴之间形成如图 3 所示的免疫沉淀线; RMV 为三条, 其中近抗原孔穴的那条架 色最深, RMV 外壳蛋白为两条, RMV 亚基单体为一条; 从移动距离来看, 亚基单体沉淀线和 外壳蛋白其中一条沉淀线离抗原孔穴最远, 反映出分子量越小的蛋白质在相同的电泳条件下 移动速度越快. 这些免疫沉腚线显示, 不同聚集形态的 RMV 蛋白亚基具有不同的抗原专化 性. 如将 RMV 抗血清换成 RMV 亚基单体抗血清,三种抗原液不变,进行同样条件的对流免 疫电泳, 则形成如下的免疫沉淀线, RMV 亚基单体一条, RMV 外壳蛋白一条, RMV 两条 (图 4), 引人注意的是: 在图 $3 \mathrm{RMV}$ 抗原液孔穴边染色最深的那条沉淀线不 再 呈 现. 比 较图 3 与图 4 可以看出, RMV 粒体、RMV 外壳蛋白与亚基单体抗血清没有形成免度沉腚 
线, RMV 粒体与 RMV 抗血清形成的沉淀线颜色最深. 当以 RMV 和 RMV 亚基单体进行 电泳，尔后滴加亚基单体抗血清进行免疫扩散得结果如图 5, 亚基单体免疫沉 淀 线弧度大, 距离宽, RMV 的沉淀线较窄小, 两者部位也有差别, 从沉淀线的绝对长度计算, 亚基单体比 病毒粒体长得多, 则说明病毒粒体抗原液中有能与亚基单体抗血清起免疫反应的成份.如果将 蛋白亚基组集较多的聚集体称为盘状体, 而将蛋白亚基组集较少的聚集体称为低聚体, 那么 似乎亚基单体数组集越大, 与亚基单体的抗原专化性差异就越烈, 最终, 病毒粒体与亚基单体 抗血清不发生免疫沉淀反应, 而那些组集较少的低聚体仍有可能与亚基单体抗血清发生免疫 沉淀反应. 当病毒粒体溶液和亚基单体溶液分孔同时电泳, 然后加入 $\mathrm{RMV}$ 抗血清进行免疫 扩散,得图 6 的结果, 亚基单体与病毒粒体溶液都能和 RMV 抗血清反应. 这一结果与图 3 和 图 4 并不矛盾. 作者认为亚基单体的那条沉淀线是 RMV 抗原溶液中自行释放的游离亚基单 体激发机体产生相应抗体而形成的, 这一点可以进一步用实验来说明. 在 RMV 溶液中加人 过量的亚基单体抗血清 $\left(\mathrm{V}_{\mathrm{Ab}} / \mathrm{V}_{\mathrm{Ag}} \geqslant 3\right)$, 充分吸收反应后, 进行双向免疫扩散, 得图 7a 的结

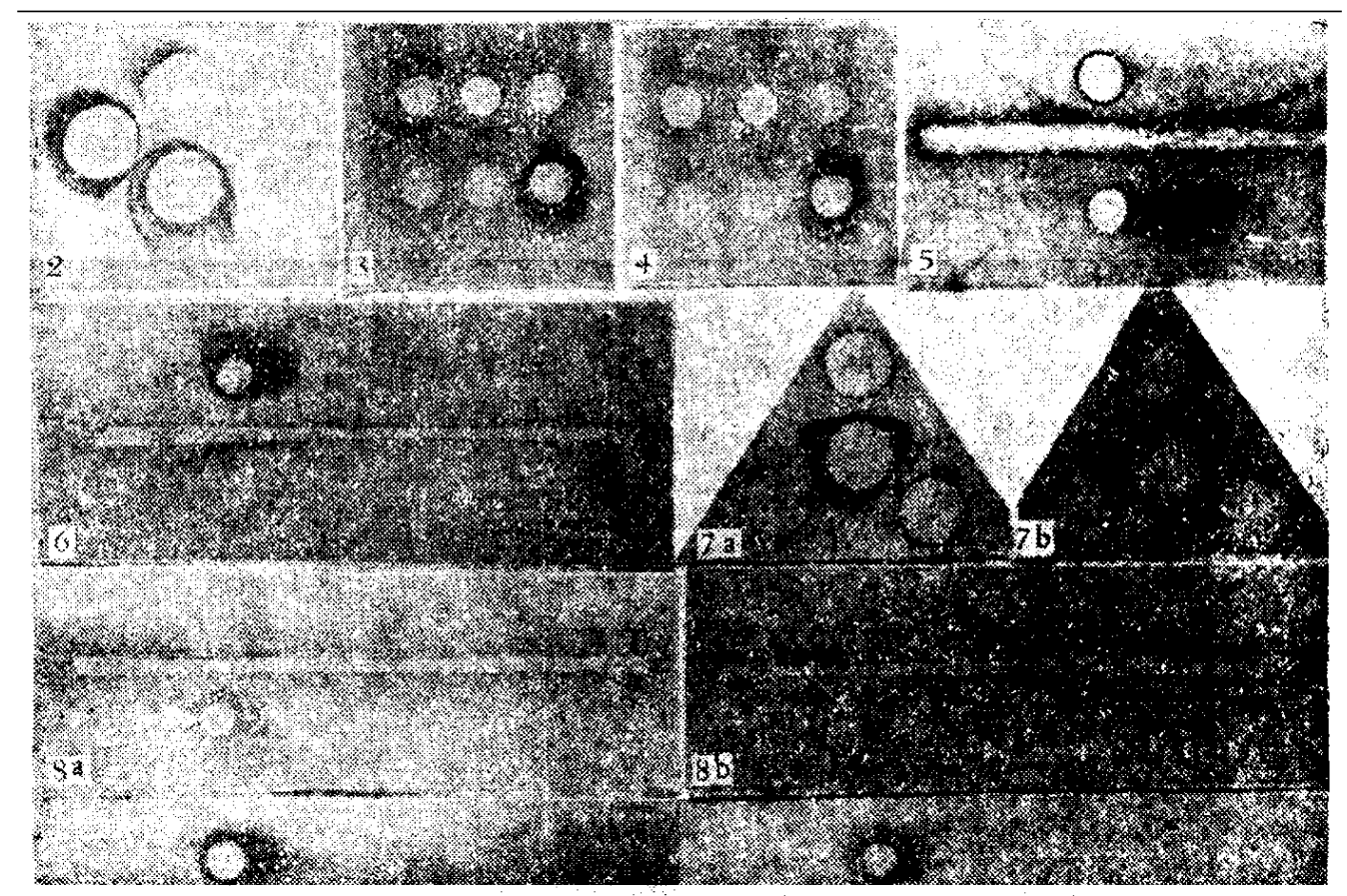

图 2-9

2. 双向免度扩散: 左孔穴为病毒溶液,右孔穴为亚基单体浚液, 上孔穴为外完蛋白浴液, 下孔 穴为病毒抗血清；3. 对流免度电泳:上排孔穴为病毒抗血清, 下排左为亚基单体溶液, 中为外 壳蛋白溶液，右为病毒溶液；4. 对流免度电泳：上排孔穴为亚基单体抗血清，下排左为亚基 单体溶液，中为外壳䖪白熔液，右为病毒溶液；5. 免疫电泳：上孔穴为亚基单体溶液，中间 槽为亚基单体抗血清，下孔穴为病綮溶液；6. 免度电泳：上孔穴为亚基单体溶液，中间梅为 病淎抗血清，下孔穴为病毒溶液；7 . 双向免度扩散: 中间孔穴为亚基单体抗血清吸收后的病 毒溶液, 上孔穴为病毒抗血清, 左孔穴为亚基单体抗血清, 右孔穴为外壳蛋白抗血清; 7b. 双 向免度扩散: 中间孔穴为健兔血清处理后的病毒溶液, 上、左、在孔穴同 7a; 8a. 吸收兔度电 泳：上孔穴为亚基单体溶液，下孔穴为病毒溶液(经健兔血清处理)，中间槽为亚基单体抗血清; 8b. 吸收免度电泳: 上孔穴为亚基单体溶液, 下孔穴为病毒溶液 (经亚基单体抗血清处理), 中 间槽为亚基单体抗血清; 9a. 吸收免度电泳: 上孔穴为病毒溶液,下孔穴为亚基单体溶液, 中 间楮为病毒抗血清 (经生理盐水处理)；9b. 吸收免度电泳：上孔穴，下孔穴同 9a, 中间楼为 病繁抗血清(经亚基单体溶液吸收) 
果. 在 RMV 抗血清孔穴和外壳蛋白抗血清孔穴处均形成明显的免疫沉淀线, 而亚基单体抗 血清孔穴处就没有沉淀线. 如果在 RMV 抗原液中加入同样量的健兔血清, 不管如何充分吸 收,进行双向免度扩散,在 RMV 抗血清、外壳蛋白抗血清, 亚基单体抗血清孔穴处均形成明 显的免度沉淀线 (图 7b). 我们从吸收免度电泳中得到相同的结果, 图 8a 是亚基单体与 RMV 抗原液(经过两倍体积的健兔血清处理)分孔同时电泳后与亚基单体抗血清经免度扩散均形成 沉淀线; 如果用两倍体积的亚基单体抗血清处理 RMV 抗原液, 只有亚基单体产生沉淀线, 而 RMV 抗原液不再出现沉淀线 (图 8b). 图 9a 和 $b$ 是 RMV 抗原液和亚基单体分孔同时电泳 后, 分别与加入两倍体积生理盐水的 RMV 抗血清及加入两倍体积亚基单体 $(1 \mathrm{mg} / \mathrm{ml})$ 的 RMV 抗血清进行免疫扩散得到的实验结果,亚基单体能与生理盐水混合的 RMV 抗血清产生 沉腚线,但不能与亚基单体吸收的 RMV 抗血清产生沉淀线,进一步说明亚基单体与 RMV 粒 体的抗原专化性确实不同。

国外许多学者对病恝及其蛋白亚基的抗原专化性进行了探讨, 结合我们对 RMV 蛋白亚 基不同聚集形态对抗原专化性的作用的研究，作者提出下述看法：由相同蛋白亚基装配成的 病毒粒体,其抗原性并不等于各个蛋白亚基抗原性的总和。病毒外壳蛋白亚基单体的抗原性， 病毒外壳蛋白盘状体的抗原性、病毒粒体的抗原性互不相同．组装成盘状体的亚基单体越多， 该盘状体的抗原专化性越与亚基单体的抗原专化性相异. 从空间构型来看, 由蛋白亚基装配 成的病毒粒体,有可能把亚基单体上某些抗原专化性的肽链包衰起来,从而形成病毒外売蛋白 亚基的隐位决定簇; 另外, 这样的病毒粒体, 暴露在各个蛋白亚基表面的具有抗原专化性的肽 链也可能因装配成粒体而发生构型上的变化,继而引起抗原专化性的变化,产生不同于该蛋白 亚基单体外表面抗原决定簇的新抗原决定簇, 即形成病毒粒体外表面抗原决定簇. 因此,可以 设想,除了通过改变蛋白亚基一定基酸的成份改变其抗原专化性外,也可以不改变蛋白亚基 氮基酸的成份而仅仅改变蛋白亚基的空间排列构型就能改变其抗原的专化性.

致谢: 朱孔生、蒋彩珍提供部分病毒外壳蛋白，傅文瑜、诸美萍摄影，生物系电镜室、离心 机空协助工作,特此致谢.

[1] Van Regenmortel, M. H. V. et al., Virology, 52(1973), 89-104.

[2] Van Regenmortel, M. H. V. et al., Anumal Review of Phytopathololgy, 16(1978), 57-81.

[ 3 ] Francki, R. I. B. et al., Virology, 48(1972), 309-315.

[4] Von Wechmar, M. B. et al., Virology, 34 (1968), 36-45.

[5]徐来升等，上海农业科技，140(1980)，28-31.

[6] 朱培坤等, 歪且学报 (自然科学版), 20(1981), 192-198.

[ 7 ] Fraenkel-conrat, H., Virology, 4(1957), 1-4. 